Revista Brasileira de Higiene e Sanidade Animal Brazilian Journal of Hygiene and Animal Sanity

ISSN: 1981-2965

\title{
Caracterização fenotípica de biofilme e resistência antimicrobiana de estafilococos coagulase positiva presentes em leite pasteurizado sob inspeção estadual ${ }^{1}$
}

\author{
Phenotypic characterization of biofilm and antimicrobial resistance of coagulase positive \\ staphylococci present in pasteurized milk under state inspection]
}

\section{${ }^{2}$ Jana Kelly dos Santos, ${ }^{3}$ Ludmilla Santana Soares e Barros, ${ }^{4}$ Elizabeth Sampaio Medeiros, ${ }^{4}$ Thayná Milena Siqueira Silva, ${ }^{4}$ Karla Danielle Almeida Soares, ${ }^{5}$ Artur Eustáquio da Silva}

Resumo. - O leite é uma fonte alternativa de proteínas acessíveis à população de baixa renda, que geralmente é carente em proteína de origem animal, comprovando a importância socioeconômica deste alimento. Em saúde pública, em particular na área de vigilância sanitária de alimentos, o $S$. aureus, o principal dos estafilococos coagulase positiva, é considerado um dos mais frequentes causadores de surtos de doenças transmitidas por alimentos. O leite e derivados estão entre os alimentos mais envolvidos nos surtos identificados e estudados. Objetivou-se com este estudo avaliar a qualidade de leite pasteurizado com inspeção estadual pela pesquisa de estafilococos coagulase positiva, sua resistência antimicrobiana e a capacidade de formar biofilme. $\mathrm{O}$ estudo foi realizado em Alagoas e foram colhidos $75 \mathrm{~L}$ de leite pasteurizado, de três estabelecimentos e de três lotes diferentes, nos municípios Maceió, Coruripe, Capela, Chã Preta e Quebrangulo. Realizou-se a pesquisa de estafilococos coagulase positiva (ECP) utilizando o meio Agar Baird-Parker e BHI. Das 75 amostras, foram identificadas 4(5,3\%) amostras com ECP. A contagem variou de $1,2 \times 10^{4}$ a $2,6 \times 10^{5} \mathrm{UFC} / \mathrm{mL}^{-1}$. Os ECP foram submetidos ao antibiograma por meio da inoculação em Caldo Müeller Hinton e aplicados os discos com as drogas: gentamicina $(5 \mu \mathrm{g})$, amoxicilina $(10 \mathrm{mcg})$, polimixina $(300 \mathrm{mg})$, eritromicina $(10 \mu \mathrm{g})$, penicilina $(10 \mu \mathrm{g})$, ampicilina $(10 \mu \mathrm{g})$, tetraciclina $(30 \mu \mathrm{g})$, sulfazotrim $(25 \mu \mathrm{g})$ e cefalexina $(30 \mu \mathrm{g})$. Realizou-se também a caracterização fenotípica dos ECP pelo método de aderência em placa de ELISA para formação de biofilme. Os estafilococos coagulase positiva isolados apresentaram 100\% sensibilidade a todos os antimicrobianos testados e nenhum foi formador de biofilme. A qualidade do leite pasteurizado com inspeção estadual do estudo com relação à presença de estafilococos coagulase positiva não é adequada para o consumo. A sensibilidade dos estafilococos a todos antimicrobianos e a não formação de biofilme diminui o risco que esses microrganismos poderiam ocasionar à saúde pública.

Termos de indexação: alimento; doença, microrganismo

Abstract: Milk is an alternative source of proteins accessible to the low income population, which is generally lacking in animal protein, proving the socioeconomic importance of this food. In public health, particularly in the area of sanitary food surveillance, Staphylococcus aureus, the main staphylococci of positive coagulase, is considered one of the most frequent cause of outbreaks of foodborne diseases. Milk and milk products are among the foods most involved in the outbreaks identified and studied. The objective of this study was to evaluate the quality of pasteurized milk with state inspection by the positive coagulase staphylococci, its antimicrobial resistance and the ability to form biofilm. The study was carried out in Alagoas and $75 \mathrm{~L}$ of pasteurized milk were collected from five processing plants and three different lots in the municipalities of Maceió, Coruripe, Capela, Chã Preta and Quebrangulo. Positive coagulase staphylococci (PCS) was performed using Baird-Parker Agar medium, rabbit plasma and brain-heart infusion broth. The PCS were submitted to the antibiogram by means of inoculation in Müller Hinton broth and the discs were applied with the drugs: gentamicin $(5 \mu \mathrm{g})$, amoxicillin $(10 \mathrm{mcg})$, polymyxin $(300 \mathrm{mg})$, erythromycin $(10 \mu \mathrm{g})$, penicillin $(10 \mu \mathrm{g})$, ampicillin $(10 \mu \mathrm{g})$, tetracycline $(30 \mu \mathrm{g})$, sulfazotrim $(25 \mu \mathrm{g})$ and cephalexin $(30 \mu \mathrm{g})$. The phenotypic characterization of PCS was also performed by the ELISA plate adhesion method for biofilm formation. Of the 75 samples, 4 (5.3\%) samples were identified 
with PCS. The count ranged from $1,2 \times 10^{4}$ a $2,6 \times 10^{5} \mathrm{CFU} / \mathrm{mL}^{-1}$. Isolated PCS showed $100 \%$ sensitivity to all antimicrobials tested and none were biofilm forming. The quality of pasteurized milk with state inspection of the study in relation to the presence of coagulase positive staphylococci is inadequate for consumption. The sensitivity of PCS to all antimicrobials and nonbiofilm formation reduces the risk that these microorganisms could cause to public health.

Index terms: food; disease; microrganismo

Autor para correspondência: E-mail: jana.santos@ifal.edu.br

Recebido em 10.02.2018. ?Aceito em 30.06.2018

http://dx.doi.org/10.5935/1981-2965.20180018

2 Instituto Federal de Alagoas (IFAL), Rua 17 de Agosto s/n, Centro, Satuba, AL 57120-000, Brasil. Pesquisa de mestrado.*Autor para correspondência: jana.santos@ifal.edu.br.

3 Universidade Federal do Recôncavo da Bahia (UFRB), Av. Rui Barbosa 710, Centro, Cruz das Almas, BA 44.380-000

4 Universidade Federal Rural de Pernambuco (UFRPE), Rua Dom Manoel de Medeiros s/n, Dois Irmãos, Recife, PE 52171-900

5 Centro Universitário (CESMAC), Rodovia Divaldo Suruagy s/n, Quadra 4, Lote Marechal Deodoro, AL 57160-000

\section{Introdução}

Durante o processamento do leite é realizada a pasteurização com o objetivo de eliminar os microrganismos patogênicos que possam contaminá-lo tornando-o um produto inócuo ao consumo humano e diminuir sua carga bacteriana a limites aceitáveis, de acordo com normatização específica (BRASIL 2017).

Apesar de a legislação brasileira não exigir para o leite a enumeração de estafilococos coagulase positiva (ECP), sua pesquisa é reconhecida internacionalmente como um padrão microbiológico de segurança de alimentos e importante indicador das condições higiênico-sanitárias da sua produção e conservação (RESTA E OLIVEIRA 2013). Entre as espécies coagulase positiva, destaca-se a bactéria patogênica Staphylococcus aureus, que são cocos gram-positivos pertencente à família Micrococcaceae, imóveis e apresentam-se frequentemente agrupados em cacho de uva (SABIONI ET AL.1988; CERQUEIRA 1994，CÂMARA 2001; FRANCO E LANGRAF 2003; JAY 2005).

Usualmente é identificado apenas o grupo estafilococos coagulase positiva, uma vez que a maioria das estirpes enterotoxigênicas de $S$. aureus produzem a enzima coagulase (DESMARCHELIER et al. 1999). Por isso tem por objetivo substituir a determinação de Staphylococcus aureus (BRASIL 2001).

O método de eleição para enumeração dos estafilococos em alimentos é o método de contagem em placas utilizando o ágar Baird - Parker. Este ágar combina o telurito de potássio $(0,01 \%)$, glicina $(1,2 \%)$ e cloreto de lítio $(0,5 \%)$ como agentes seletivos $\mathrm{e}, \mathrm{a}$ 
redução do telurito de potássio e a hidrólise da gema de ovo como características diferenciais das colônias típicas e atípicas de estafilococos. Desta forma, as colônias típicas são aquelas negras, brilhantes, delimitadas e com dois halos, sendo associada estas características a capacidade do microrganismo em produzir a enzima coagulase, e consequentemente ser um potencial produtor de enterotoxina (SANTANA ET AL. 2006, SILVA ET AL. 2007). Os mecanismos de aquisição de resistência podem ser classificados em dois grupos: mutação em genes presentes no cromossomo bacteriano ou aquisição de genes de resistência de outros microrganismos, através dos processos de transdução, transformação ou conjugação (ITO et al., 2003).

Objetivou-se com este trabalho avaliar qualidade de leite pasteurizado com inspeção estadual pela pesquisa de estafilococos coagulase positiva, sua resistência antimicrobiana e a capacidade de formar biofilme.

\section{Material e Métodos}

\section{Local de estudo.}

O estudo foi realizado na região Nordeste do Brasil, no estado de Alagoas. Foram colhidas amostras em usinas de beneficiamento localizadas em Maceió,
Coruripe, Capela, Chã Preta e Quebrangulo, no período de outubro de 2016 a maio de 2017.

Amostragem. Em Alagoas há oito usinas de beneficiamento produtores de leite pasteurizado com inspeção estadual. Em três destes estabelecimentos não foi possível realizar as colheitas devido à suspensão da produção ocasionada por longo período de seca na região. Foram coletados 15 litros de leite pasteurizado em cada um dos 5 estabelecimentos, divididos em três lotes de $5 \mathrm{~L}$, com intervalo de no máximo 21 dias entre coletas, totalizando 75 amostras $[(5+5+5) \times 5]$. As amostras foram colhidas no setor de expedição de cada estabelecimento, no dia de sua produção.

As amostras foram transportadas em caixas isotérmicas para o Laboratório de Inspeção de Alimentos da Universidade Federal Rural de Pernambuco e analisadas em no máximo 24h após serem processadas nos estabelecimentos.

\section{Pesquisa de Staphylococcus coagulase positiva.}

A metodologia utilizada para a pesquisa de SCP foi a preconizada pela ISO 6888-2 (1999) por meio do método horizontal de estafilococos coagulase positiva. 


\section{Avaliação da resistência antimicrobiana.}

Os quatro ECP isolados foram submetidos ao antibiograma por meio da inoculação em Caldo Müeller Hinton seguindo a metodologia descrita pelo CLINICAL AND LABORATORY STANDARDS INSTITUTE (2012). Logo após, foram aplicados os discos impregnados com os seguintes antimicrobianas: gentamicina $(5 \mu \mathrm{g})$, amoxicilina (10mcg), polimixina $(300 \mathrm{mg})$, eritromicina $(10 \mu \mathrm{g})$, penicilina $(10 \mu \mathrm{g})$, ampicilina $(10 \mu \mathrm{g})$, tetraciclina $(30 \mu \mathrm{g})$, sulfazotrim $(25 \mu \mathrm{g})$ e cefalexina $(30 \mu \mathrm{g})$. As amostras foram classificadas, de acordo com a susceptilidade, em resistentes, sensíveis e de sensibilidade intermediária. Caracterização fenotípica de Staphylococcus spp. para a capacidade de formar biofilme. A avaliação fenotípica de produção de biofilme foi avaliada de acordo com o procedimento descrito por Stepanovic et al. (2000). Foi realizada a leitura a $620 \mathrm{~nm}$ em um equipamento de ELISA.

\section{Resultados}

Das 75 amostras de leite analisadas, foram identificadas 4(5,3\%) amostras com estafilococos coagulase positiva, de três estabelecimentos e lotes diferentes.

Observou-se que apenas dois estabelecimentos apresentaram todas as 15 amostras negativas para ECP (Tabela $1)$.

Tabela 1 - Frequência de amostras positivas e contagem de ECP $\left(\mathrm{UFC} / \mathrm{mL}^{-1}\right)$ por lote e estabelecimento.

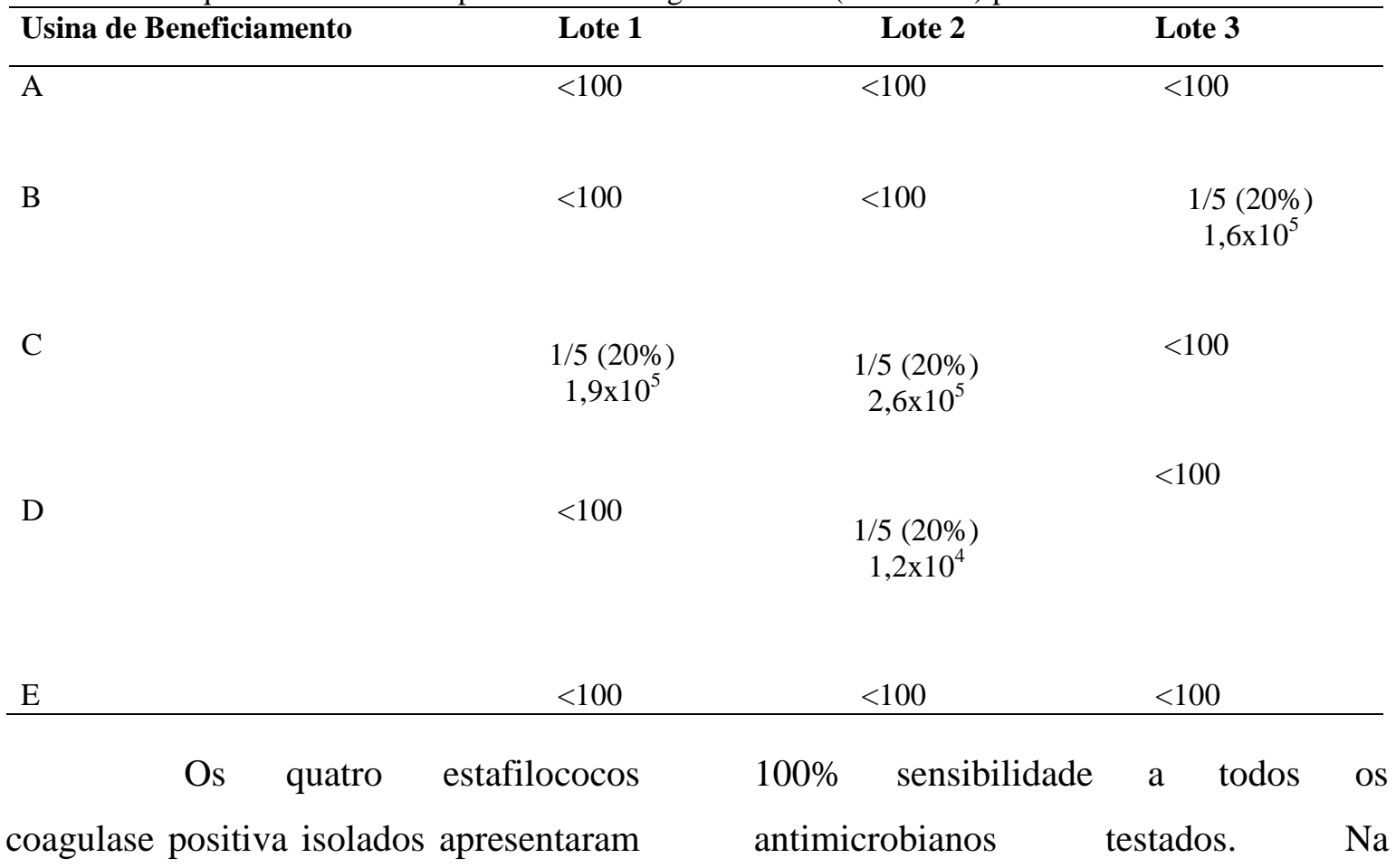


caracterização fenotípica todos ECP apresentaram a densidade óptica maior ou igual ao controle negativo no leitor de ELISA. Portanto, nenhum isolado foi formador de biofilme.

\section{Discussão}

Os estafilococos coagulase positiva encontrados nas amostras indicam falhas do binômio tempo/temperatura durante a pasteurização industrial; matéria-prima excessivamente contaminada, sanificação deficiente das linhas de produção, transporte e armazenamento em temperaturas inadequadas, e/ou contaminação pós-pasteurização (OLIVEIRA 2005).

O leite cru obtido de animais com infecção estafilocócica nas glândulas mamárias (mastite) tem sido considerado a principal fonte de cepas $S$. aureus, podendo contaminar excessivamente a matéria-prima. Mota et al (2012) isolaram de 1080 amostras de leite bovino bactérias do gênero Staphylococcus em 291(39,3\%), sendo destes isolados $37(12,7 \%)$ como ECP.

A presença de ECP é preocupante considerando que o leite já havia passado por tratamento térmico e estava pronto para o consumo. Estima-se ser necessário a ingestão de $10^{5}$ UFC de Staphylococcus spp. por grama ou mililitro de alimento para provocar sinais de toxi-infecção (Cardoso 1985; Bergdoll 1989; Gandra et al. 2016). Neste estudo entre as 4 amostras positivas, 3 estavam acima deste valor.

A RDC $n^{\circ} 12$, de 2 de janeiro de 2001, da ANVISA, estabelece os padrões microbiológicos para os alimentos e exige para alimentos em geral que o limite permitido para ECP seja de $10^{3} \mathrm{UFC} / \mathrm{mL}^{-}$ 1. Porém, para o leite não há esta exigência, o que poderia ser reavaliado considerando que mesmo no produto pronto para consumo é encontrado o microrganismo.

É importante ressaltar também que a ausência de células viáveis de Staphylococcus spp. no momento da análise de amostras não assegura que o produto esteja livre de enterotoxinas estafilocócicas, devido à sua termoestabilidade. Entretanto, a detecção de enterotoxinas diretamente nos alimentos é difícil de ser utilizada na rotina laboratorial devido ao seu alto custo (RESTA E OLIVEIRA 2013).

No Brasil, conforme Ataíde et al. (2008), a média das contagens de Staphylococcus coagulase positiva no leite cru foi $3,9 \times 10^{4} \mathrm{UFC} / \mathrm{mL}^{-1}$, valor menor que o encontrado nesta pesquisa 
com leite pasteurizado.

Estudos demonstram que três espécies de ECP, $S$. aureus, $S$. hyicus e $S$. intermedius já estiveram envolvidas em vários surtos de intoxicação alimentar e são capazes de produzir enterotoxinas e coagulase (Gandra et al. 2016). Segundo de Freitas Guimarães et al. (2013), as espécies de ECP com maior potencial enterotoxigênico foram $S$. aureus $(32,2 \%)$ e S. hyicus $(47,4 \%)$.

Como agravante, o consumidor desse leite pasteurizado com inspeção estadual é, em sua maioria, a população carente, abrangida pelo programa de governo do estado, que tem menos recursos para cuidar da saúde.

Todos os isolados de ECP foram sensíveis a todos os antimicrobianos, permitindo o tratamento eficaz com qualquer uma dessas drogas que fosse utilizada em caso de infecção estafilocócica. Resultados diferentes foram encontrados por Medeiros et al. (2009), que encontraram $35 \%$ dos ECP sensíveis a todos os antimicrobianos. Costa et al. (2013) observaram que apenas 4,54\% dos isolados testados, distribuídos entre oito rebanhos, foram sensíveis a todos os antimicrobianos testados.

Em outra pesquisa, a resistência dos ECP à penicilina $\mathrm{G}$ foi de $36,0 \%$; à ampicilina de $34,0 \%$ e à oxacilina de 16,7\% (DE FREITAS GUIMARÃES 2015).

Com relação a virulência, nenhum ECP apresentou capacidade de formar biofilme. Em contrapartida, Peixoto et al. (2015) caracterizaram todos os isolados de ECP em leite como produtores de biofilme, classificados fortes formadores de biofilme, uma vez que, apresentaram DO acima de no mínimo quatro vezes a DO do seu respectivo controle. Corroborando com os 98\% (96/98) dos isolados de $S$. aureus produtores de biofilmes com o método Ágar Vermelho Congo encontrados por PENA E UFFO (2013).

Convém destacar que essas amostras são destinadas ao Programa do Leite no Estado de Alagoas e, portanto, seus fornecedores têm $\mathrm{o}$ dever de produzir alimento seguro e com qualidade, não somente pelo valor nutricional, como também no aspecto de higiene.

Este fato é de particular importância, pois o público-alvo deste programa é bastante susceptível a enfermidades transmitidas por alimentos (SILVA et al. 2008).

A realização de análises, incluindo a enumeração de estafilococos coagulase positiva, antes de o produto 
processado ir para o consumo, pode evitar riscos à saúde pública.

E, além das autoridades sanitárias, os produtores rurais, indústrias de beneficiamento e estabelecimentos de comercialização de produtos alimentícios, ou seja, todos os envolvidos na cadeia alimentar, têm a responsabilidade em fornecer alimentos seguros à população (GIOVA 1997).

\section{Conclusões}

A qualidade do leite pasteurizado com inspeção estadual do estudo com relação à presença de estafilococos coagulase positiva não foi adequada para o consumo. A sensibilidade dos estafilococos a todos antimicrobianos e a não formação de biofilme diminui o risco que esses microrganismos poderiam ocasionar à saúde pública.

\section{Referências}

1. ATAÍDE W.S.; MACIEL J.F., LIMA P.L.A.; et al. 2008. Avaliação microbiológica e físico-química durante o processamento do leite pasteurizado. Revista do Instituto Adolfo Lutz, 67(1): 73-77.

2. BERGDOLL, M.S. Staphylococcus aureus. In: Foodborne bacterial pathogens. New York: Marcel Dekker, p.463-523, 1989.

3. BRASIL. Resolução RDC ${ }^{\circ} 12$, de 2 de janeiro de 2001. Aprova o "Regulamento técnico sobre padrões microbiológicos para alimentos". Órgão emissor: ANVISA Agência Nacional de Vigilância Sanitária.
4. BRASIL. Decreto $\mathrm{n}^{\circ}$ 9.013, de 29 de março de 2017. Regulamento de Inspeção Industrial e Sanitária de Produtos de Origem Animal. Diário Oficial da União 3003 2017; 1(1):3-27.

5. CARDOSO, V.M.; SILVA, G.G.; CANO, V. Contagem de microrganismos. In: Análise Microbiológica de Alimentos. Rio de Janeiro, Quimitra, p. 20-27. 1985.

6. CÂMARA, S.A.V. Surtos de Toxinfecções Alimentares no Estado de Mato Grosso do Sul, 1998-2001. 2001, 79f. Monografia (Especialização em Saúde Pública) - Escola de Saúde Pública Dr. Jorge David Nasser, Campo Grande.

7.CERQUEIRA, M.M.O.P.; SOUZA, M.R.; FONSECA, L.M.; RODRIGUES, R.; RUBINICH, J. 1994. Surto epidêmico de toxiinfecção alimentar envolvendo queijo tipo Minas Frescal em Pará de Minas. Arquivo Brasileiro de Medicina Veterinária e Zootecnia. Belo Horizonte, 46 (6): 723-728.

\section{CLINICAL AND LABORATORY} STANDARDS INSTITUTE (CLSI). Performance standards for antimicrobial susceptibility testing: 22st informational supplement M100-S22. Wayne, PA: CLSI; 2012.

9. COSTA, G.M.; BARROS, R.A.; CUSTÓDIO, D.A.C; et al. 2013. Resistência a antimicrobianos em Staphylococcus aureus isolados de mastite em bovinos leiteiros de Minas Gerais, Brasil. Arq. Inst. Biol., São Paulo, 80(3): 297-302.

10. DESMARCHELIER, P.M.; HIGGS, G.M.; MILLS, L.; SULLIVAN, A.M.; VANDERLINDE, P.B. 1999. Incidence of coagulase positive Staphylococcus on beef carcasses in three Australian abattoirs. International Journal of Food Microbiology, 47:221-229.

11. DE FREITAS GUIMARÃES F; NÓBREGA D.B, RICHINI-PEREIRA V.B.; et al. 2013. Enterotoxin genes in coagulasenegative and coagulase-positive staphylococci isolated from bovine milk. J Dairy Sci. 96(5): 2866-72. 
12. FRANCO, B.D.G.M., LANDGRAF, M. Microbiologia dos Alimentos. ATHENEU: São Paulo. 182p. 2003.

13. GANDRA, E.A.; FERNANDEZ, M.A.; SILVA, J.A.; et al. 2016. Detection by multiplex PCR of Staphylococcus aureus, $S$. intermedius and $S$. hyicus in artificially contaminated milk. Cienc. Rural, Santa Maria, 46(8):1418-1423.

14. GIOVA, A.T (trad.). APPCC na qualidade e segurança microbiológica de alimentos. São Paulo: Varela, 1997.

14. INTERNATIONAL ORGANIZATION FOR STANDARDIZATION (ISO). ISO 6888-2:1999. Microbiology of food and animal feeding stuffs -- Horizontal method for the enumeration of coagulase-positive staphylococci (Staphylococcus aureus and other species). First edition, 1999-02-15. Geneve: ISO; 1999.

15. ITO, T.; OKUMA K.; MA X.X.; YUZAWA H.; HIRAMATSU K. 2003. Insights on antibiotics resistance of Staphylococcus aureus from its whole genome: genomic island. Drug Resistance Updates 6(1):41-52.

16. JAY, J. Microbiologia de alimentos. Porto Alegre: Artmed, 2005. p. 52-55, 471485.

17. MEDEIROS, E.S.; MOTA, R.A; SANTOS, M.V; et al. 2009. Perfil de sensibilidade microbiana in vitro de linhagens de Staphylococcus spp. isoladas de vacas com mastite subclínica. Pesq. Vet. Bras., Rio de Janeiro, 29(7): 569-574.

18. MOTA, R.A.; DE MEDEIROS, E.S.; DOS SANTOS, M.V; JÚNIOR, J.W.P.; MOURA, A.P.B.L; COUTINHO, L.C.A. 2012. Participação dos Staphylococcus spp na etiologia das mastites em bovinos leiteiros no estado de Pernambuco (Brasil). Ci. Anim. Bras., Goiânia, 13(1):124-130.

19. OLIVEIRA, R.P.S. Condições microbiológicas e avaliação da pasteurização em amostras de leite comercializadas no município de Piracicaba-SP. 2005. $81 \mathrm{f}$.
Dissertação (Mestrado em Ciência de Alimentos), Universidade de São Paulo, São Paulo. 2005.

20. PEIXOTO, M.M.R.; GRESSLER, L.T; SUTILI, F.J; et al. 2015. Ação dos desinfetantes sobre a adesão e biofilme consolidado de Staphylococcus spp. Pesq. Vet. Bras., Rio de Janeiro, 35(2): 105-109.

21. PENA, J; UFFO, O. 2013.Producción de biofilme en genotipos de Staphylococcus aureus aislados de mastitis bovina en Cuba. Rev Salud Anim., La Habana, 35(3):189-196.

22. RESTA, M.S.A.; OLIVEIRA, T.C.R.M. de. 2013. Avaliação do padrão estafilococos coagulase positiva estabelecido pela legislação brasileira para massas alimentícias. Braz. J. Food Technol., Campinas, 16(4): 319-325.

23. SABIONI, J.G.; HIROOKA, E.Y.; SOUZA, M.L.R. 1988. Intoxicação alimentar por queijo minas contaminado com Staphylococcus aureus. Revista de Saúde Pública. São Paulo, 22(5): 458-461.

24. SANTANA, E.H.W. de; BELOTI, V.; OLIVEIRA, T.C.R.M de; et al. 2006. Estafilococos: morfologia das colônias, produção de coagulase e enterotoxina a, em amostras isoladas de leite cru refrigerado. Semina: Ciências Agrárias, Londrina, 27(4): 639-646.

25. SILVA, N.; JUNQUEIRA, V.C.A; SILVEIRA, N.F.A.; et al. Manual de métodos de análise microbiológica de alimentos. $3^{\mathrm{a}}$ ed. Livraria Varela Ltda, São Paulo, 2007, n.536 p- 87,89, 138 .

26. SILVA, M.C.D.; SILVA, J.V.L.; RAMOS, A.C.S.; et al. 2008. Caracterização microbiológica e físico-química de leite pasteurizado destinado ao programa do leite no Estado de Alagoas. Ciênc. Tecnol. Aliment., Campinas, 28(1): 226-230.

27. STEPANOVIC, $S$; VUKOVIC D; DAKIC I; et al. 2000. A modified microtiterplate test for quantification of staphylococcal biofilm formation. Journal of Microbiology Methods, 40:175-179. 